\title{
Nursing Students' Self-Graded Motivation to Complete their Programme of Study
}

\author{
Margareta Warrén Stomberg and Kerstin Nilsson ${ }^{*}$
}

The Sahlgrenska Academy, University of Gothenburg, Sweden and University of Skövde, Sweden

\begin{abstract}
The aim of this study was to explore variation in nursing students' motivation to complete their programme of study, as well as factors relating to low versus high motivation and students' opinions of what would increase their motivation to complete their programme of study.

A study was carried out between April 2006 and December 2007. A total of 872 students registered in a 3-year nursing programme randomly participated in self-rating their motivation score once each semester. Descriptive statistics, statistical calculations and content analysis regarding open-ended questions were performed. Most of the students, 73\%, rated their motivation as $\geq 6$ on a 0 -10 Likert scale; and $16 \%$ gave a rating of $\leq 4$.

The desire to become a registered nurse $(\mathrm{RN})$ and having a positive attitude towards the studies were the main factors influencing high motivation to complete the programme of study. Having a negative attitude towards the studies was an explanation of decreased motivation. There was a significant decrease $(p=0.001)$ in the motivation score with respect to number of semesters, and motivation increased with the student's age $(\mathrm{p}=0.0119)$. Suggestions for increasing motivation given by those who rated their motivation as $\leq 4$ mainly focused on improvements in didactics and study organisation.
\end{abstract}

Keywords: Nurse education, motivation.

\section{INTRODUCTION}

Nursing students' motivation has proved to be related to the successful outcome of education [1]. In Sweden the RN lead to an academic degree as well as a professional degree. Consequently, it is important to investigate how nursing students assess their motivation during their studies, and to discover what factors are related to their motivation as well as what would increase their motivation if necessary.

Nursing students' reasons for choosing an education in nursing have been studied earlier and the results of the different studies seem to be related to each other, independent of culture. In Japan, nursing was considered to be a good occupational choice [2]; in Italy, job availability was given as a reason [3]; in Norway, nursing was seen as a safe job [4]; and in England, nursing students were found to be attracted by an interest in professional rewards [5]. More altruistic reasons for choosing a nursing education have also been found. Nursing is seen as a worthwhile job, providing the opportunity to serve people [2] as well as helping others, doing something useful [4] and providing human contact [2, 6]. Furthermore, extrinsic reasons have been found, such as being influenced by parents and friends [3].

However, reasons and motivation for studying nursing might change during the course of the nursing programme. The preferences of Norwegian nursing students in their nursing careers changed, from wanting to be midwives or paediatric nurses to also including working at medical/surgical and psychiatric wards. Clinical experience

*Address correspondence to this author at the Sahlgrenska Academy, University of Gothenburg, Sweden; Tel: +46 3178660 28; Fax: +46 31786 33 99; E-mail: kerstin.nilsson@sahlgrenska.gu.se and professional challenges were the reasons for their changed preferences [7]. It was found that the ones who highly valued a bachelor's degree, because it enabled them to go on to further education, were less interested in giving care and help to others. Career preferences were more often related to acute healthcare and high-tech areas than to caring for chronically ill or elderly patients [6]. Conceptions of nursing before entering the nursing programme influenced English nursing students in their decision to continue their education. Active support from knowledgeable and experienced practitioners contributed to realising their aims [8]. In an English study of 315 students, it was found that academic performance was directly influenced by the students' support-seeking behaviours. The model describing this behaviour depicted age and entry qualifications as influencing academic self-efficacy, locus of control, worries and outcome expectancy, and was seen as an important aspect of self-regulated learning. The student's supportseeking behaviour predicted his/her performance to a greater extent than entry qualifications [9].

Swedish nursing students $(n=315)$, who were in one of the semesters of their three-year nursing programme, rated their degree of motivation for their studies cross-sectionally. Their overall rating for all six semesters was $6.3(0-10)$, but there was a significant difference between semesters, with a tendency to give a lower score during the 5th semester. The main motivation factor, described in their own words, was the desire to become a registered nurse (RN) [10]. In clinical settings, nursing students' motivation for their nursing career is influenced by ward culture, mentors and learning from reflections related to observations of nursing in practice [11]. Students in clinical education have been found to be mainly motivated by achievement [12]. The benefits of feedback in 
clinical education increased student confidence, motivation and self-esteem, and also improved clinical practice [13].

It is usual that nursing students in Sweden have experience of being enrolled nurses (EN). Between 5 and $20 \%$ (variation between nursing schools) of the students have this experience [14]. No studies have focused Swedish ENs' motivation towards their nursing studies. Consequently, it may therefore be useful to turn to a study from Australia, where an investigation was made of experienced ENs who was participating in a special programme to become RNs. The participants' transition experiences were overall found to be positive, as they acquired an academic education, became critical thinkers and were socialised into the $\mathrm{RN}$ role, but the transition-to-student status was stressful [15].

Nursing students' motivation has mostly been studied in relation to the future $\mathrm{RN}$ profession. There are limited studies concerning nursing students' self-rated motivation during the course of their education.

The aim of this study was to explore variation in nursing students' motivation to compete their programme of study during their education. Further aims were to explore issues relating to low versus high degree of motivation and their opinion of what would increase their motivation.

\section{MATERIALS AND METHODS}

This study was conducted from April 2006 to June 2007 at a medium-sized university in Sweden. We searched for the status of the students' motivation to complete their studies at a fixed point of time during semester 1-6 and then described it in relation to different semesters and to the students' age. Different cohorts were asked in different semesters. A questionnaire was used, graduated with answers on a type of Likert scale together with one open-ended question. First, the students were asked to self-grade their motivation score on a scale graded from 0 to 10 , specifying the opposite extremes. The rating scale had labelled end points, where 0 indicated not motivated at all and 10 indicated highly motivated. An eleven-point scale was chosen to obtain a neutral midpoint, which is recommended for Likert scales [16]. Second, in an open-ended question, students were asked which factors influenced their motivation. On the third data collection occasion (spring 2007), a third question was added, namely: "What would increase your motivation if necessary".

\section{Data Collection}

Information concerning the study and voluntary participation was obtained. Data collection was carried out during three different periods (April 2006, December 2006 and June 2007). Students studying at semester 1-6 participated at each occasion of data collection. Data was collected during a limited period at the end of each of the three semesters, and in similar circumstances. Data were collected by both researchers during randomly visited lectures that were part of the nursing programme at the university. The same researcher informed the participants, distributed and collected the data during the same lecture.

\section{Participants}

A different cohort of students, who were registered in the university's 3-year nursing programme, running for six semesters, was asked to participate in the study once during each semester. Only students who were present at the random lecture were asked to participate and they were asked just once. A total of 872 ( $85 \%$ female and $15 \%$ male) students participated in the study and none of the invited students refused to participate. On average, 96 students registered each semester, of whom an average of $51 \%$ returned answered questions; there were no dropouts from the random present students. Since participation in lectures at Swedish universities is not compulsory, a participation rate of $51 \%$ is not uncommon.

\section{Ethics}

At the time of data collection, permission from an Ethics Committee was not required by law [17]. However, permission for this study was given by the head of department at the university, the quality assurance manager at the university, as well as the students' union [17]. In accordance with the Declaration of Helsinki, written informed consent was obtained from all participants [18]; i.e. the participants were first informed about the purpose and method of the study, and that their participation was voluntary and could be withdrawn at any time, and then gave their consent. Their answers were given anonymously.

\section{Statistics and Analysis}

All data were entered into a computerised database and processed using the Statistical Package for the Social Sciences (SPSS version 16.0). Descriptive statistics were performed, including frequency counts, percentages and means when appropriate. Statistical analyses were performed when appropriate. All tests were performed by Pitman's test, which is a non-parametric test not based on ranks but on the original values of the variables [19]. To avoid reiteration from participants, data from the $2^{\text {nd }}$ semester were used when Pitman's test was used for analysis.

Logistic regression analysis with all data included was performed to outline all the figures. The smooth curves in the figures were calculated by making use of the splinefunction in logistic regression analysis.

\section{Validity and Reliability}

A pilot study was initially performed to ensure the face validity of the questions. The participants could answer the questions anonymously. The participants thus had nothing to gain or lose by honestly answering the questions, which implied built-in reliability. A type of Likert scale was used. This type of scale is commonly used to investigate participants' grade of attitude. The validity and reliability of this instrument reflects the true score of the activity investigated [16].

The open-ended question was categorised based on a qualitative manifest content analysis. The individual answers that emerge in the text (manifest) and share the same meaning was categories in order to describe and quantify specific attitudes into fewer content-related categories sharing the same meaning. The analysis ends with the answers to: "What occurs and how often does it happen?" [20]. Data can then be compared. The analysis phase was conducted separately by the two researchers and thereafter compared until a $95 \%$ level of agreement was achieved. 


\section{RESULTS}

Table 1. Sample Demographics

\begin{tabular}{|c|c|c|c|}
\hline Semester & $\begin{array}{c}\mathbf{n} \\
\text { Female/Male }\end{array}$ & Mean Age Year & Standard Deviation \\
\hline \hline 1 & $\begin{array}{c}166 \\
137 / 29\end{array}$ & 26,1 & 6,6 \\
\hline 2 & $\begin{array}{c}207 \\
178 / 28 \\
(1 \text { missing })\end{array}$ & 27 & 6,6 \\
\hline 3 & $\begin{array}{c}156 \\
145 / 11\end{array}$ & 26,9 & 6,1 \\
\hline 4 & $\begin{array}{c}120 \\
93 / 26 \\
(1 \text { missing })\end{array}$ & 28,2 & 7,3 \\
\hline 5 & $\begin{array}{c}132 \\
105 / 26 \\
(1 \text { missing })\end{array}$ & 28,9 & 6,6 \\
\hline 6 & $\begin{array}{c}91 \\
(1 \text { missing })\end{array}$ & 31,3 & 8,7 \\
\hline
\end{tabular}

As seen in Table $\mathbf{1}$ most of the students' are female, $85.4 \%$ respectively $14.6 \%$ male students.

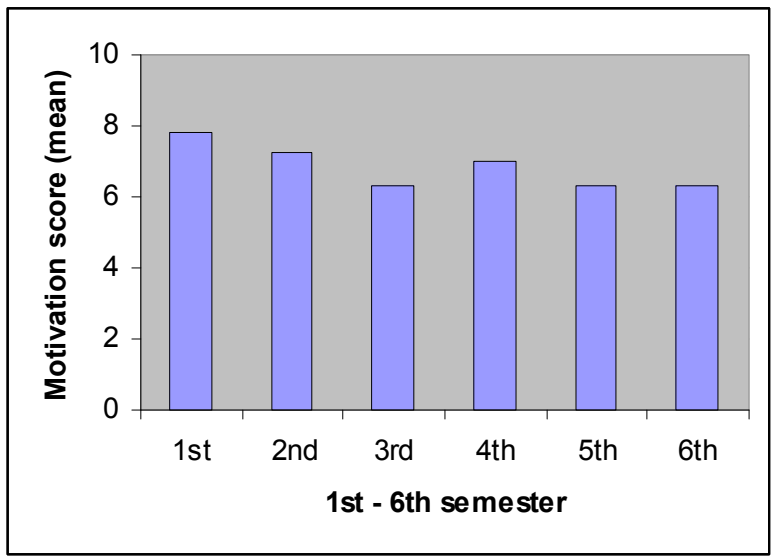

Fig. (1). Degree of motivation, semester 1-6 (mean) ( $\mathrm{n}=872)$.

There was a significant decrease in motivation score to compete their programme of study with respect to the number of semesters $(p<0.001)$. The mean score varied between 7.80 in the $1^{\text {st }}$ semester and 6.33 in the $6^{\text {th }}$ semester (Fig. 1).

The mean score varied between 7.72 in the $1^{\text {st }}$ semester and 4.86 in the $6^{\text {th }}$ semester for males; and between 7.82 in the $1^{\text {st }}$ semester and 6.42 in the $6^{\text {th }}$ semester for females. There was no significant difference between men and women with respect to motivation $(\mathrm{p}=0.5160)$ (Fig. 2).

There was a significant increase in motivation to complete the studies with age $(p=0.0119)$ (Fig. 3).

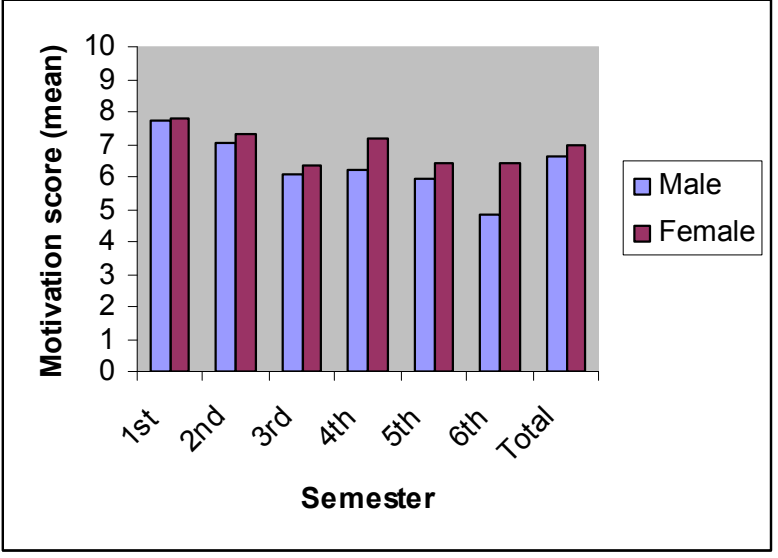

Fig. (2). Degree of motivation in $1^{\text {st }}$ to $6^{\text {th }}$ semester (mean) by male and female students ( $\mathrm{n}=872$, Male 127, Female 741, Missing 4).

Of 872 students, 637 students $(73 \%)$ rated their motivation score to complete the studies as $\geq 6$. The main factor $(44.7 \%)$ having a positive influence on students' motivation was the desire to become a registered nurse. When a motivation score of $\geq 6$ was given, $21.3 \%$ of the students also had a positive attitude towards their studies and $15.6 \%$ found the organisation of the programme stimulating.

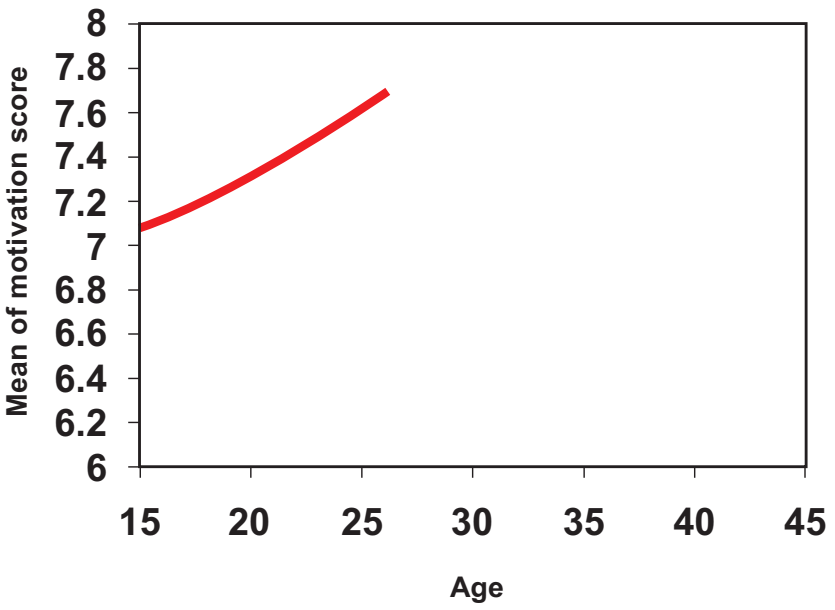

Fig. (3). Relation between motivation score and age.

Table 2. Negative Explanations for A Low Motivation Score $(\leq 4)$

\begin{tabular}{|c|c|}
\hline Negative Explanations for Low Motivation & n \\
\hline \hline Teachers who are not engaged & 2 \\
\hline Not achieving good study results & 8 \\
\hline Having a negative attitude to the studies & 22 \\
\hline Organisation of the programme not perceived as stimulating & 18 \\
\hline Degree of difficulty/ Studies experienced as too demanding & 18 \\
\hline Having a bad life situation & 15 \\
\hline Frequencies of negative explanations related to score $\leq \mathbf{4}$ & $\mathbf{8 3}$ \\
\hline
\end{tabular}

Out of 872 students, $141(16 \%)$ rated their motivation score to complete the studies as $\leq 4$. Negative attitudes 
towards their studies $(27 \%)$, as well as perceived limitations in the curriculum $(22 \%)$ and the degree of difficulty/demands made by the studies (22\%), were the main negative explanations for low motivation scores (Table 2).

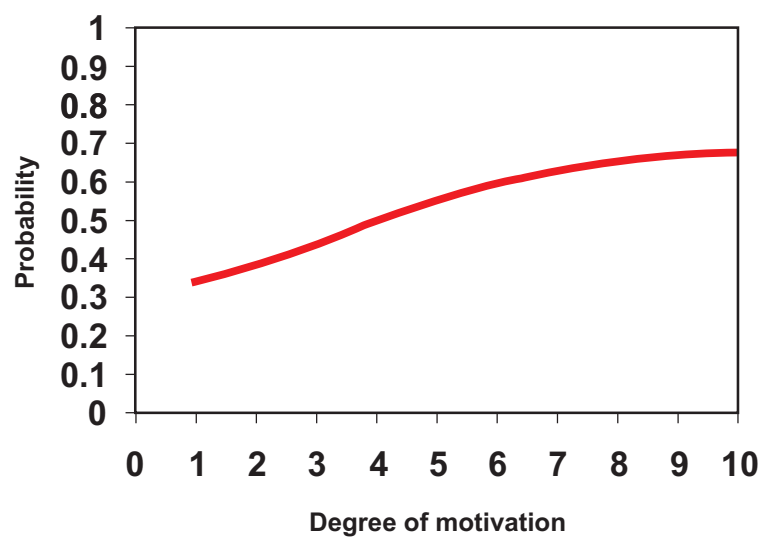

Fig. (4). Probability of knowing the reason for the degree of motivation.

There was no significant correlation between motivation scores and knowing the primary cause of what affected the motivation ( $p=0.9108)$. However, if students' motivation to complete their studies was neither extremely low nor extremely high, there was an increased probability that they knew what influenced their motivation (Fig. 4).

Table 3. Suggestions for Improving Motivation (Students Scored $\leq 4$ )

\begin{tabular}{|c|c|}
\hline Suggestions for Improving Motivation & Number \\
\hline \hline Achievement of study results & 3 \\
\hline More clinical practice & 4 \\
\hline Better social benefits for students & 6 \\
\hline Improvements in didactics and study organisation & 10 \\
\hline $\begin{array}{c}\text { Frequencies of suggestions for improving } \\
\text { motivation related to score } \leq 4\end{array}$ & 23 \\
\hline
\end{tabular}

On the last data collection occasion, the students were asked to note what might increase their motivation to complete their programme of study. Twenty-four out of 331 students who scored $\leq 4$ answered that there was nothing that could increase their motivation, and 23 answered that their motivation could increase. The different aspects of what could make them more motivated are shown in Table 3 . The main suggestions from the students for increasing motivation to complete their programme of study concerned improvements in didactics and study organisation.

Of the 221 students, who scored $\geq 6,123$ students answered that motivation could be increased, and 96 students answered that motivation could not be increased; internal missing 4 students.

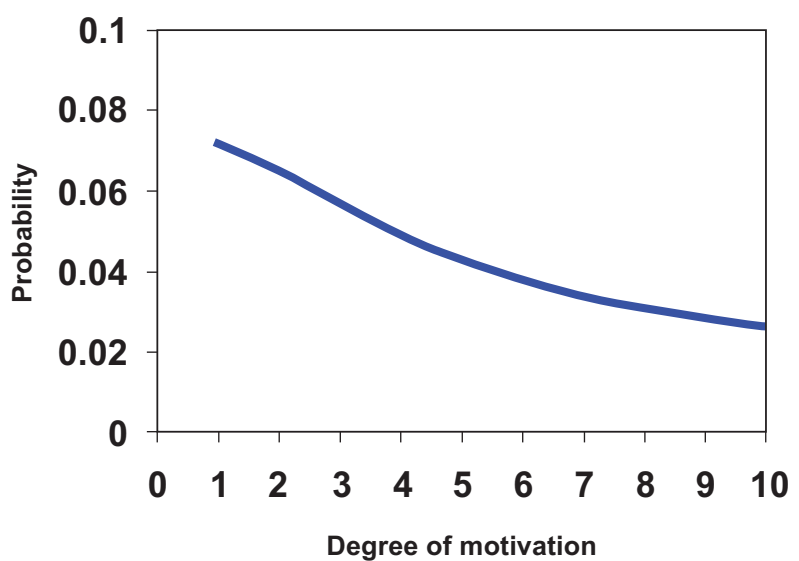

Fig. (5). Probability of not knowing what to add to increase the degree of motivation.

There was a significant correlation between motivation scores and not knowing what would increase the students' motivation to complete their studies $(p=0.0399)$, indicating an increased probability of not knowing what could increase motivation when students reported a lower degree of motivation (Fig. 5).

\section{DISCUSSION}

The nursing students' motivation scores to complete their programme of study decreased significantly with the number of semesters. Even if the scored motivation was on the upper half of the scale (mean 6.33) in the $6^{\text {th }}$ semester, the question is why there was a decrease in motivation. The occupation of RN has been seen as a good occupational choice [2], with good job availability [3], and Rongstads (2002) found that students were motivated by the opinion that nursing was a safe job. One explanation for the students' decreased motivation could be that in Sweden, during the years when the data were collected, the role of $\mathrm{RN}$ could no longer be seen as a job associated with high availability, a good salary or job security, since being employed as an RN directly after completing one's nursing education could not be taken for granted. Several students had to wait for a post with conditional tenure, and in the mean time had to find temporary employment. These facts could cause future insecurity and therefore convey less hope for the future, thereby reducing motivation. This is supported by studies which found that insecure work situations are stressful and influence mental health [21, 22]. Furthermore, a feeling of salary lag and salary gap could contribute to nurses' distrust of their employers in times of downsizing [23]. Another explanation could be that the transition from being a student to being an RN might be frightening. This explanation is supported by an English study where it was found that being an RN was a fraught time [24]. The necessity to facilitate the transition from student to $\mathrm{RN}$ has been found earlier [25], as a university education can never prepare the individual for a specific workplace [26]. If this transition were facilitated, nursing students' motivation would also presumably increase. 
There was no significant difference between men and women with respect to motivation to complete their programme of study in this study, even if male nursing students rate their motivation lower over the years. The reason for male students' lower degree of motivation could be related to results from an Australian study of factors influencing academic and clinical practice performance of male nursing students [27]. Stott found that male nursing students could feel isolated and excluded from academic and clinical perspectives; instead, they were more engaged in the technical aspects of nursing. If the nursing curricula fail to meet male nursing students' needs during their education there could be a risk of lower motivation. Males' interest in technical aspects of nursing could be explained by theories of men's and women's socialisation to different gender patterns, i.e. technical and economic vs care and responsibility [28]. These patterns of socialisation need to be raised to the level of consciousness in nursing education, otherwise there is a risk that the students' careers will follow these gender patterns [29].

Students' degree of motivation increased significantly with age. Experience from other study programmes and/or work experience might influence students' motivation as they grow older. Over $40 \%$ of the student body has this experience in Sweden [30] and $10-20 \%$ of Swedish nursing students have experience as ENs [14]. Probably their experience made them secure in their choice of education and also provided an understanding of the content in (helped them understand the content of?) courses related to practice. Age has been found to influence students' understanding of subjects in relation to public health [31]. Likewise, Ofori \& Charlton (2002) found a relation between age and supportseeking and its outcome in the form of study performance. The question of age could also be discussed in relation to high degree of motivation. An obvious positive motivation factor in this study was qualifying as an RN. This is in accordance with Robbins, who found that motivation for nursing studies requires high levels of effort to achieve educational goals [32]. Among the 637 students (out of 872) who rated their motivation $\geq 6$, the main motivation factor was the desire to become a registered nurse. However, not only older students but also younger ones rated their motivation as high. Nearly half the students mention a desire to become an $\mathrm{RN}$; this is a factor that has previously been found to motivate nursing students. Reasons given for this have been professional reward [5], the opportunity to serve people [2], as well as helping others and doing something useful [4] and providing human contact [2,6]. If nursing students are to retain their desire to be RNs it is important for the educator to create a curriculum that promotes student motivation and relates the education programme to their forthcoming profession. The relation between the theoretical and practical acquisition of knowledge could be questioned. Enhanced confidence in the clinical area helps to bridge the theory-practice gap [33]. Do Swedish nursing students get enough practice-based education? Some students in this study answered that they did not.

As nursing studies today are not teacher-controlled in all areas of learning, the studies require active, independent and self-directed learning. This may be experienced as demanding and thus may influence students' degree of motivation. Support from supervisors on goal orientation, conditioned by individual need, would help students to maintain their motivation. To achieve good study results, the supervisor may communicate to the students that their current competence and skill will continue to develop [34]. The main suggestion from the students for increasing motivation dealt with improvements in didactics and study organisation. Consequently, it is important to improve nursing education curricula in compliance with students' opinions of what constitutes good didactics. Being able to influence the study programme seems to be important [35]. Nurse educators thus need to have an open mind to new forms of didactics as well as flexible learning.

Accordingly, students look to the future. Young people frequently look ahead and have a positive and optimistic view of the future. A newly published study based on 7,500 questionnaires sent to people aged 16-74 years found that $80 \%$ of young people (16-29 years) view their future optimistically [35]. A positive belief in the future probably also influences attitudes towards studies. This may explain that one fifth of the students with ratings of $\geq 6$ had a positive attitude towards their studies.

Another factor in this study, which had a negative influence on motivation, was when students' life situations were not congruent with the study process. The ability of students to control their own lives (internal locus of control) is an issue that is important for motivation [36]. Another issue could be that they have financial difficulties. $70-80 \%$ of Swedish students receive grants and loans from the government [37], and students need to work during their education to cover their cost of living. In Sweden, the largest financial burden for students consists of housing costs, which account for $45 \%$ of their total costs [30].

A limitation of this study is that, as we were not able to survey the same students at each point when data collection took place, their views were not necessarily representative of the whole cohort. Those who were present might have had either particularly high or low motivation to complete their programmes of study, and it is possible that at one data collection point there was a group of very highly motivated students, whilst at another the students present were particularly poorly motivated. This makes comparisons between the groups tenuous and threatens the internal validity of the study. Another limitation could be that the study had too few questions to capture several dimensions of motivation.

\section{CONCLUSIONS}

Motivation scores to complete their study programme decreased significantly with the number of semesters during the nursing students' 3-year education. The degree of motivation increased significantly with age. The desire to become a nurse had a positive influence on studies, while improvements in didactics and study organisation could help to increase motivation when it was given a low rating. This result indicates the importance of creating curricula that promote student motivation, and of meeting the students individually during the study programme to discuss their study situation and possible misgivings about their future profession, which might influence their motivation. 


\section{REFERENCES}

[1] Dearnley C, Matthew B. Factors that contribute to undergraduate student success. Teach Higher Educ 2007; 12(3): 377-91.

[2] Yokoyama M, Iwai I, Oota K, Kaharu C, Misao H. [St. Luke's College of Nursing: student's motivation for selecting both nursing program and St. Luke's College for study]. Seiroka Kango Daigaku Kiyo 1996; 22: 72-80.

[3] Costantino V, Perissinotto E, Scattolin A, Vian F. Motivation and expectations of graduate nursing students at the university of Padova. Professioni Infermieristiche 2000; 53(1): 17-25.

[4] Rongstad M-K. Recruitment to and Motivation for Nursing Education and the Nursing Profession. J Nurs Educ 2002; 41(7): 321-25.

[5] Miers ME, Rickaby CE, Pollard KC. Career choices in health care: is nursing a special case? A content analysis of survey data. Int $\mathbf{J}$ Nurs Stud 2007; 44(7): 1196-209.

[6] Rognstad MK, Aasland O, Granum V. How do nursing students regard their future career? Career preferences in the post-modern society. Nurse Educ Today 2004; 24(7): 493-500.

[7] Kloster T, Hoie M, Skar R. Nursing students' career preferences: a Norwegian study. J Adv Nurs 2007; 59(2): 155-62.

[8] Spouse J. An impossible dream? images of nursing held by preregistration students and their effect on sustaining motivation to become nurses. J Adv Nurs 2000; 32(3): 730-9.

[9] Ofori R, Charlton JP. A path model of factors influencing the academic performance of nursing students. Issues Innovations Nurs Educ 2002; 38(5): 507-15.

[10] Nilsson K, Warrén Stomberg M. Nursing students motivation towards their studies - a survey study. BMC Nurs 2008; 7: 6 .

[11] Pearcey AP, Elliott EB. Student impressions of clinical nursing. Nurse Educ Today 2004; 24(5): 382-7.

[12] Mrayyan TM, Modallal R, Awamreh K, Atoum M, Abdullah M, Suliman S. Readiness of organizations for change, motivation and conflict-handling intentions: Senior nursing students' perceptions. Nurse Educ Pract 2008; 8(2): 120-8.

[13] Clynes MP, Raftery SE. Feedback: An essential element of student learning in clinical practice. Nurse Educ Pract 2008; 8(6): 405-11.

[14] Stölten C, Tursell A, Persson E, Wictorsson T, Raak R, Markström A-M. Report concerning abridged time for education in nursing and teacher education. Linköping, Malmö, Umeå Univeristies 2006.

[15] Rapley PA, Nathan P, Davidson L. EN to RN: the transition experience pre- and post-graduation. Rural Remote Health 2006; 6(1): 363.

[16] Polit DF, Tatano Beck CT. Nursing Research. Principles and Methods. 7th ed. Philadelphia: Lippincott Williams \& Wilkins 2006.

[17] SFS. The act of ethical trail of research concerning humans. Stockhom: Ministry of Education and Research 2003; 460.

[18] World Medical Association. Declaration of Helsinki. Ethical principles for medical research involving human subjects. Nurs Ethics 2002; 9(1): 105-9.

[19] Good P. Permutation, parametric and bootstrap tests of hypotheses. New York: Springer 2005.
[20] Krippendorff K. Content analysis: an introduction to its methodology. $2^{\text {nd }}$ ed. Beverly Hills, Calif.: Sage 2004.

[21] Hellgren J. The times they are a-changin': job uncertainty and the flexible labor market. (PhD. Dissertation). Stockholm: Stockholm University, Dept. of Psychology 2003.

[22] Ferrie JE, Shipley MJ, Newman K, Stansfeld SA, Marmot M. Selfreported job insecurity and health in the Whitehall II study: potential explanations of the relationship. Soc Sci Med 2005; 60(7): 1593-602.

[23] Hertting A, Nilsson K, Theorell T, Larsson US. Downsizing and reorganization: demands, challenges and ambiguity for registered nurses. J Adv Nurs 2004; 45(2): 145-54.

[24] Whitehead J. Newly qualified staff nurses' perceptions of the role transition. Br J Nurs 2001; 10(5): 330-9.

[25] Standing M. Clinical decision-making skills on the developmental journey from student to Registered Nurse: a longitudinal inquiry. J Adv Nurs 2007; 60(3): 257-69.

[26] Bowden J, Marton M. The University of Learning. Beyond Quality and Competence in Higher Education. London: Kogan Page 1998.

[27] Stott A. Exploring factors affecting attrition of male students from an undergraduate nursing course: a qualitative study. Nurse Educ Today 2007; 27(4): 325-32.

[28] Ve H. Rationality and identity in Norwegian feminism. In: von der Fehr D, Rosenbeck B, Jònasdòttir GA, Eds. Is there a Nordic feminism? London: UCL Press 1998; pp. 325-43.

[29] Nilsson K, Sätterlund Larsson U. Conceptions of Gender - a study of Female and Male Head Nurses statements. J Nurs Manag 2005; 13(2): 179-86.

[30] Eurostudent. Social and Economic Conditions of Student Life in Europe 2008.

[31] Hirano K, Ikeda N, Kanagawa K, et al. [Survey on public health nursing education-in the comparison of nursing education courses, universities, advanced courses for public health nurse with junior nursing colleges, and public health nursing school]. Nippon Koshu Eisei Zasshi 2005; 52(8): 746-55.

[32] Robbins SP. Basic motivation concepts. In: Robbins SP, Ed Organizational Behavior, Concepts, Controversies, and Applications Englewood Cliffs, NJ: Prentice Hall Inc 1996; pp. 210-49.

[33] Borlase J, Abelson-Mitchell N. User perceptions of the knowledge underpinning practice orientation dial (KUPOD) as a tool to enhance learning. Nurse Educ Pract 2008; 8(1): 9-19.

[34] Ofori R. Measuring motivational orientations toward supportseeking: the development and predictive validity of the Motives for Tutorial Support-Seeking Questionnaire. Nurse Educ Today 2006; 26(3): 228-39.

[35] The Swedish National Board for Youth Affairs. Young people with attitude. Attitude and value survay 2007. Stockholm: The Swedish National Board for Youth Affairs 2007.

[36] Perrot LJ, Deloney LA, Hastings JK, Savell S, Savidge M. Measuring Student Motivation in Health Professions' Colleges. Adv Health Sci Educ 2001; 6(3): 193-203.

[37] Bienefeld S, Almqvist J. Student Life and the Roles of Students in Europe. Eur J Dent Educ 2004; 39(4): 429-41.

(C) Warrén Stomberg and Nilsson; Licensee Bentham Open.

This is an open access article licensed under the terms of the Creative Commons Attribution Non-Commercial License (http://creativecommons.org/licenses/by$\mathrm{nc} / 3.0 /$ ) which permits unrestricted, non-commercial use, distribution and reproduction in any medium, provided the work is properly cited. 